\title{
Postnatal Development of Flash Visual Evoked Potentials in the Jaundiced Gunn Rat ${ }^{1}$
}

\author{
SARAH SILVER, JAIME KAPITULNIK, AND HAIM SOHMER \\ Departments of Physiology [S.S., H.S.] and Pharmacology [J.K.], Hebrew University-Hadassah Medical School, \\ Jerusalem, Israel
}

\begin{abstract}
In this study, the postnatal development of flash visual evoked potential (VEP) has been monitored in the jaundiced (jj) Gunn rat model of neonatal hyperbilirubinemia to determine whether this evoked response is affected by bilirubin-induced neurotoxicity. VEP could first be recorded at $\mathbf{1 6} \mathrm{d}$ of age. The $\mathrm{jj}$ rats exhibited prolonged wave latencies and lower wave amplitudes during the 3 rd wk of postnatal life, when compared with their nonjaundiced littermates. There was no correlation at $21 \mathrm{~d}$ of age between VEP parameters and either bilirubin levels or body weight. About one third of the $\mathrm{jj}$ animals died between 21 and $28 \mathrm{~d}$ of age. The average VEP wave latencies at 21 $d$ of age of the rats who were to die was prolonged compared with those of rats who survived till at least $28 \mathrm{~d}$ of age. Thus, the latency of VEP waves at the age of $21 \mathrm{~d}$ appears to be related to the further outcome of $\mathrm{jj}$ Gunn rats. Although wave amplitudes were lower in $\mathbf{j j}$ as compared with nonjaundiced 21-d-old animals, there were no amplitude differences between the $\mathrm{jj}$ rats who would die and those who would survive during the 4th wk of life. These findings may contribute to the understanding of the pathogenesis of bilirubin encephalopathy in the neonatal period. (Pediatr Res 30: 469-472, 1991)
\end{abstract}

\section{Abbreviations}

VEP, visual evoked potential

ABR, auditory nerve and brain-stem response

ij, jaundiced

$\mathrm{Jj}$, nonjaundiced

Bilirubin, a neurotoxic degradation product of $\mathrm{Hb}$, enters the brain after excessive elevation of its levels in blood, and, in connection with complications such as hypoxia and acidosis, it may cause various degrees of brain damage. The resulting condition, bilirubin encephalopathy, leads to the impairment of motor, sensory, and behavioral functions. The pathogenesis of bilirubin encephalopathy has not been so far fully elucidated. The severe nature of the neurologic sequelae of neonatal hyperbilirubinemia has stimulated the search for reliable and accurate means of following the kinetics of bilirubin entry into the brain, predicting the nature and extent of the subsequent damage caused by this neurotoxin, and preventing this neurotoxicity by

Received September 4, 1990; accepted June 14, 1991

Correspondence: Prof. J. Kapitulnik, Department of Pharmacology and Experimental Therapeutics, Hebrew University-Hadassah Medical School, POB 1172 Jerusalem 91010 , Israel.

I Part of a Ph.D. thesis to be submitted by S.S. to the Senate of the Hebrew University. A preliminary report of this study was presented at a meeting of the Israel Society of Physiology and Pharmacology in Jerusalem, Israel in December 1989 and at the annual meeting of the Society for Pediatric Research in Anaheim, CA in May 1990 (Pediatr Res 27:345A. 1990). appropriate therapeutic intervention. The availability of a functional marker capable of detecting early and, hopefully, reversible shifts of bilirubin from blood to brain would be of great value in preventing even the minimal manifestations of neonatal brain damage, e.g. learning disabilities and behavioral deficits (1-3).

The ABR has been studied in human neonates with hyperbilirubinemia because hearing loss is one of its sequelae (4-7). Reversible as well as permanent changes in ABR patterns have been observed in conjunction with neonatal jaundice (8-12). Much of the experimental research in this field has been conducted on the homozygous recessive ji Gunn rat model (13-16). This mutant of the Wistar rat develops severe congenital hyperbilirubinemia immediately after birth as a result of its inability to conjugate bilirubin with glucuronic acid, which is the normal pathway for excretion of this neurotoxin in the $\mathrm{Jj}$ animal. Some jj Gunn rats die before reaching adulthood, and the survivors exhibit clear signs of bilirubin encephalopathy.

Shapiro and Hecox (17) have recently studied the development of $A B R$ in Gunn rats. The ABR abnormalities observed in ij Gunn rats by these authors were minimal. Because these and similar ABR studies conducted in other animal models of neonatal hyperbilirubinemia (18) have not yielded uniform and conclusive results, we have attempted to assess an additional developing neural pathway, the visual pathway.

The present report describes the postnatal development of the flash VEP in $\mathrm{jj}$ and Jj Gunn rats. The VEP, which is generated in the visual cortex, has been extensively used for detecting both short- and long-term effects of the perinatal exposure to neurotoxic chemicals (19-21). Our results suggest that VEP may be of value in assessing the severity of bilirubin-induced neurotoxicity.

\section{MATERIALS AND METHODS}

Animals. jj and $\mathrm{Jj}$ Gunn rats were obtained from our colony at the Hebrew University-Hadassah Medical School. Female Jj rats were mated with $\mathrm{jj}$ males, and the resulting litters contained about the same numbers of $\mathrm{jj}$ and $\mathrm{Jj}$ pups. The offspring were kept with the mother for $4 \mathrm{wk}$ at a constant room temperature of $23-25^{\circ} \mathrm{C}$ and a $12 \mathrm{~h}$ light $-12 \mathrm{~h}$ dark cycle and were fed rat food containing $11 \%$ fat (Weizmann Institute, Rehovot, Israel) and water ad libitum.

VEP. Animals were weighed and anesthetized by ether inhalation. Body temperature was maintained at $36-37^{\circ} \mathrm{C}$ with a heating pad and monitored with a telethermometer (Yellow Springs Instrument Co., Yellow Springs, OH). The VEP was recorded with a specially adapted Micro-Shev C-ERA 100 evoked response system (Micro-Shev, Efrat, Israel). The VEP was elicited by high intensity $(\times 16)$ flashes delivered by a Grass PS- 2 photostimulator (Grass Instruments, Quincy, MA) triggered by the evoked response system at a rate of $0.5 / \mathrm{s}$. Flash duration was 10 $\mu \mathrm{s}$. The flash lamp was placed at a distance of $15-20 \mathrm{~cm}$ from the animal's head. The electrical activity was recorded by means of subdermal needle electrodes (Grass Instruments) placed at the occipital region and chin, with a ground electrode placed at the 
hind limb, filtered (band pass $0.8-30 \mathrm{~Hz}$ ), amplified, and averaged $(n=64)$. Duplicate VEP were recorded in response to flash stimuli and compared with a control recording obtained by shielding the lamp. Typical VEP recordings showing waves $\mathrm{P}_{1}$, $N_{1}$, and $P_{2}$ are presented in Figure 1 . The average latencies and amplitudes of each of these waves were calculated.

Plasma bilirubin. Plasma bilirubin was determined by the method of Michaelsson (22).

Results are presented as mean $\pm \mathrm{SD}$, and statistical evaluation was performed using $t$ test and repeated measures analysis of variance.

\section{RESULTS}

Experiment 1: development of $V E P$. A group of $12 \mathrm{jj}$ and 12 $\mathrm{Jj}$ pups, originating from four litters, were examined at 16,18 , 21 , and $28 \mathrm{~d}$ of age and compared with $12 \mathrm{jj}$ and $14 \mathrm{Jj}$ adult (3$4 \mathrm{mo}$ old) Gunn rats. Eight $\mathrm{jj}$ and $10 \mathrm{Jj}$ rats were alive at the age of $28 \mathrm{~d}$. At this age, the jj rats were significantly smaller $(50.6 \pm$ $3.6 \mathrm{~g}$, mean $\pm \mathrm{SD})$ than their $\mathrm{Jj}$ littermates $(59.5 \pm 2.7 \mathrm{~g} ; p<$ $0.001)$.

Typical VEP recordings obtained between 16 and $28 \mathrm{~d}$ of age are shown in Figure 1. VEP could first be recorded on d 16 in nine out of the $12 \mathrm{jj}$ and in nine out of the $12 \mathrm{Jj}$ animals. However, wave $P_{1}$ was not present at this time in an additional three $\mathrm{jj}$ and two $\mathrm{Jj}$ rats and was inconsistently recorded during further development. The latencies of all three VEP waves markedly shortened after $d 16$ (Fig. 2). In the $J j$ rats, waves $P_{1}$ and $N_{1}$ reached their adult latency values by $d 21$, whereas the latency of wave $\mathrm{P}_{2}$ continued to decrease beyond this age. In the jj rats, there were significantly longer latencies for waves $N_{1}$ and $P_{2}$ at $18 \mathrm{~d}$ of age and for all three VEP waves on $\mathrm{d} 21$, compared with the $\mathrm{Jj}$ rats (Fig. 2). No differences in latency between $\mathrm{jj}$ and $\mathrm{Jj}$ rats were observed in either 28 -d-old or adult animals.

The amplitudes of waves $\mathrm{N}_{1}$ and $\mathrm{P}_{2}$ initially increased and later decreased toward the adult values, which were similar to those obtained on d 16 (Fig. 3). Jaundiced rats exhibited lower amplitudes for wave $N_{1}$ at $21 \mathrm{~d}$ of age and for wave $P_{2}$ at 16 and $18 \mathrm{~d}$ of age, compared with the $\mathrm{Jj}$ rats (Fig. 3).

Experiment 2: prognostic significance of VEP in jj Gunn rats. Retrospective analysis of the data obtained in the developmental

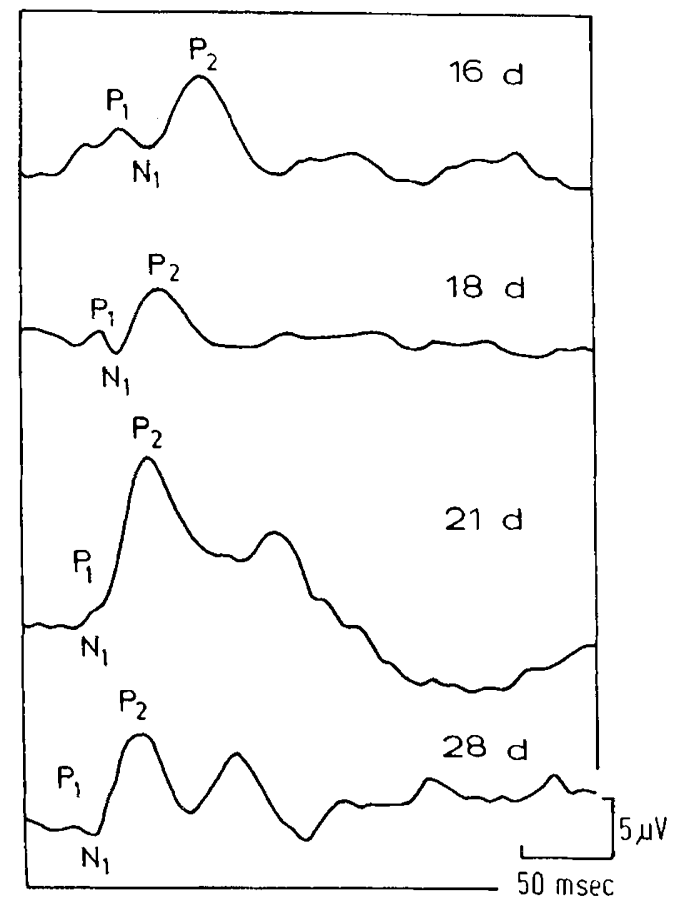

Fig. 1. Flash VEP patterns during postnatal development of a Jj Gunn rat. The VEP was recorded as described in Materials and Methods.
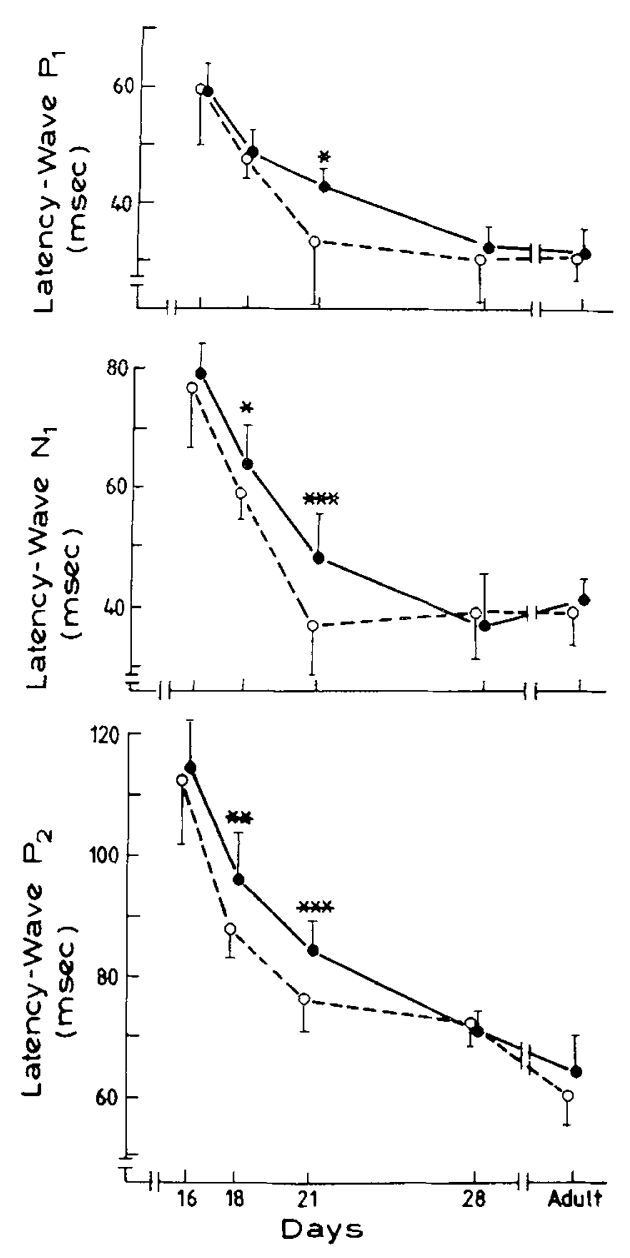

Fig. 2. VEP wave latencies during postnatal development of $\mathrm{jj}$ and $\mathrm{Jj}(\mathrm{O}) \mathrm{Gunn}$ rats. Differences between means are statistically significant at: ${ }^{*} p<0.05 ;{ }^{* *} p<0.025$; and ${ }^{* *} p<0.005$.

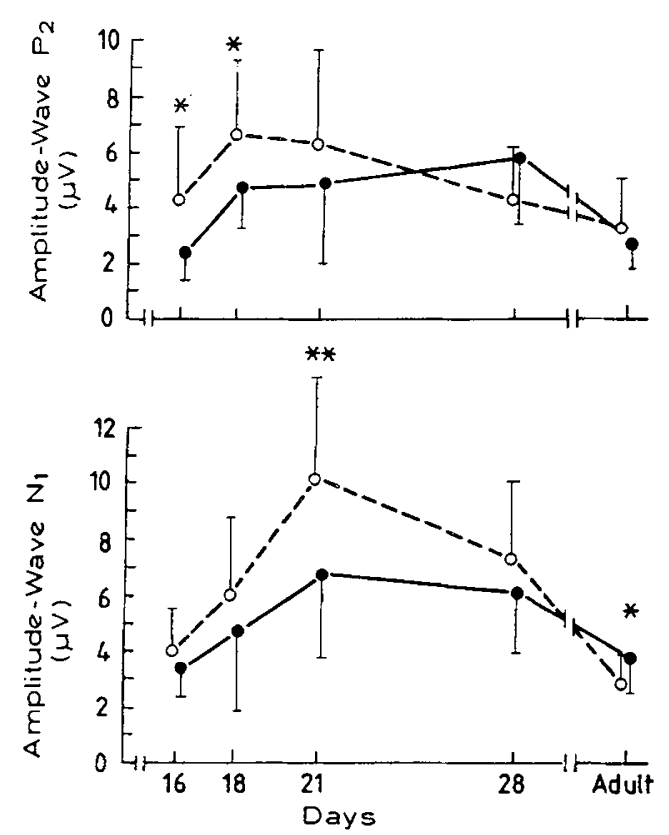

Fig. 3. VEP wave amplitudes during postnatal development of $\mathrm{jj}(\bullet$ and $\mathrm{Jj}(\mathrm{O})$ Gunn rats. Differences between means are statistically significant at: ${ }^{*} p<0.025$; and ${ }^{* *} p<0.01$. 
study (experiment 1 ) revealed that three out of the four nonsurviving $\mathrm{jj}$ animals died between 21 and $28 \mathrm{~d}$ of age. These three animals showed a trend toward longer latency values and lower amplitudes when compared at $21 \mathrm{~d}$ of age with the eight $\mathrm{jj}$ animals that remained alive for at least another $7 \mathrm{~d}$. We therefore extended the study to a much larger population totaling $34 \mathrm{jj}$ and $32 \mathrm{Jj}$ rats, which were examined at 21 and $28 \mathrm{~d}$ of age. Eleven out of the $34 \mathrm{jj}$ rats died during this period. In these 11 rats, the average latencies of waves $\mathrm{N}_{1}$ and $P_{2}$ on $\mathrm{d} 21$ were significantly longer ( $p<0.005$ and $p<0.01$, respectively) than those observed for the $23 \mathrm{jj}$ rats that were still alive on $\mathrm{d} 28$ (Fig. 4). The latter exhibited the same average latency for $\mathrm{N}_{1}$, and a slightly longer latency for $\mathrm{P}_{2}(p<0.05)$, when compared with the $\mathrm{Jj}$ heterozygotes. On $\mathrm{d} 28$, there were no differences in latencies between the $\mathrm{Jj}$ and the surviving jj rats (Fig. 4), confirming the earlier results obtained in the developmental study (Fig. 2 ). The amplitudes of waves $N_{1}$ and $P_{2}$ were significantly smaller for 21 -d-old $\mathrm{jj}$ rats as compared with their $\mathrm{Jj}$ littermates $(p<$ 0.01 and $p<0.025$, respectively), but there were no differences in amplitude values at this age between the $\mathrm{jj}$ rats who would die and those who would survive during the $21-28 \mathrm{~d}$ age period (Fig. 5). The $11 \mathrm{jj}$ rats who died between 21 and $28 \mathrm{~d}$ of age weighed less on $\mathrm{d} 2 \mathrm{l}(23.4 \pm 4.0 \mathrm{~g})$ than the $23 \mathrm{jj}$ survivors $(32.5 \pm 8.4 \mathrm{~g}$; $p<0.025)$, whereas the latter did not differ from the $\mathrm{Jj}$ rats $(33.4$ $\pm 5.7 \mathrm{~g})$

To determine whether VEP parameters are correlated with serum bilirubin levels or body weight, a separate group of $48 \mathrm{jj}$ animals was studied on $\mathrm{d} 21$. No such correlations were found. Moreover, in 12 of these rats who died during the 4th wk of life, plasma bilirubin levels $(13.46 \pm 3.42 \mathrm{mg} / \mathrm{dL} ; 230.17 \pm 58.48$
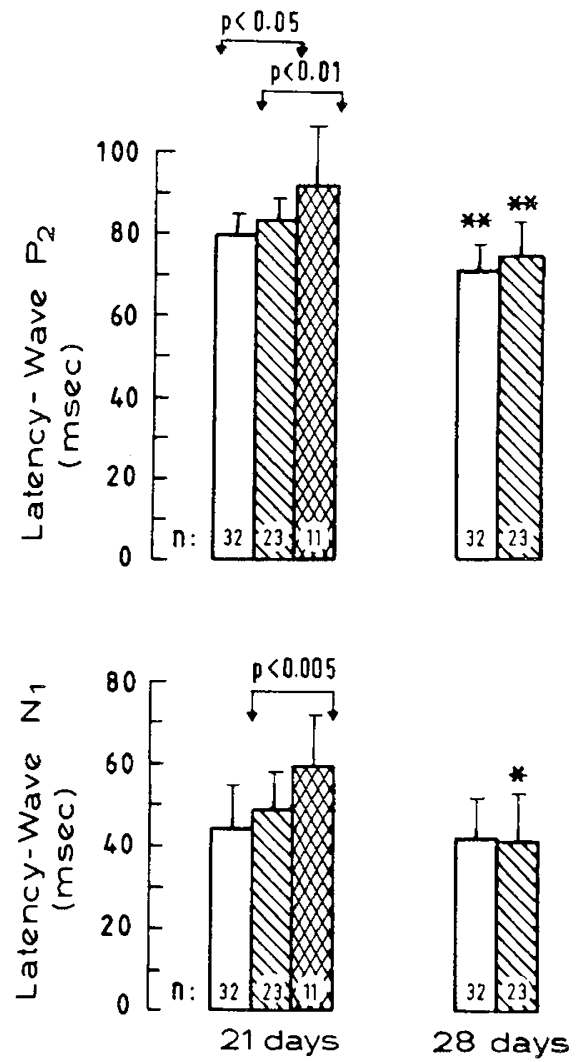

Fig. 4. VEP wave latencies as related to the survival of Gunn rats during the 4th wk of life. jj rats that were still alive on d $28(\mathbb{\mathbb { N }})$ were compared, on $\mathrm{d} 21$, with jj rats that died between 21 and $28 \mathrm{~d}$ of age (图) and with Jj rats ( $\square$ ). Statistically significant differences between the means of any two of these three groups are indicated on top of the bars. Average latencies on $\mathrm{d} 28$ for groups of animals that survived are statistically different from their latencies at $21 \mathrm{~d}$ of age: ${ }^{*} p<0.01$; and ${ }^{* *} p<0.001$.
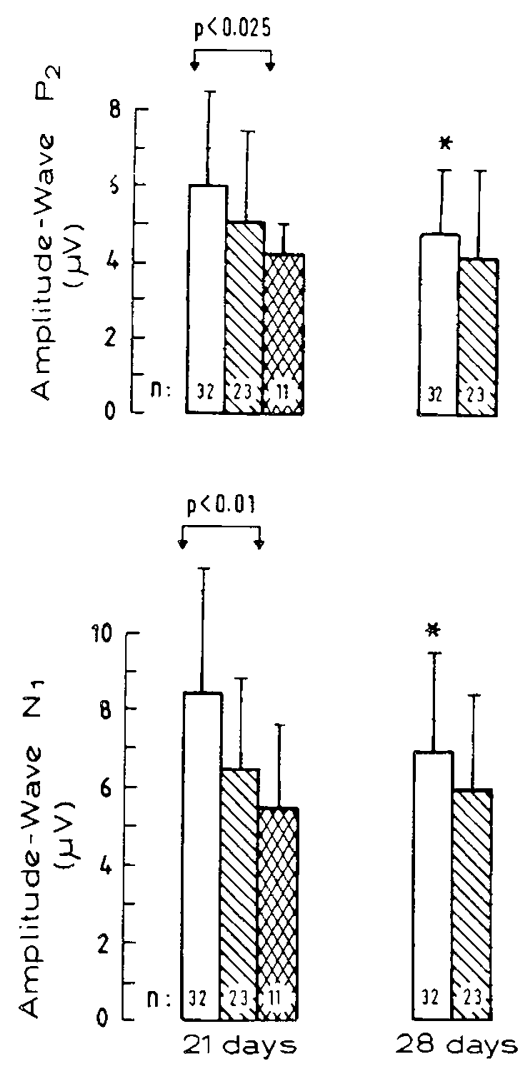

Fig. 5. VEP wave amplitudes as related to the survival of Gunn rats during the 4th wk of life. See Figure 4 for details of animal groups. Average amplitudes are statistically different between 28 and $21 \mathrm{~d}$ of age at ${ }^{*} p<0.025$.

$\mu \mathrm{mol} / \mathrm{L}$ ) did not differ from those of the 36 survivors (13.04 \pm $3.13 \mathrm{mg} / \mathrm{dL} ; 222.98 \pm 53.52 \mu \mathrm{mol} / \mathrm{L}$ ).

\section{DISCUSSION}

The present study of flash VEP in Gunn rats was designed to assess the effects of neonatal hyperbilirubinemia on the postnatal development of the visual pathway. ji Gunn rats exhibited significantly prolonged average VEP wave latencies and reduced amplitudes when compared with their $\mathrm{Jj}$ littermates during the $3 \mathrm{rd}$ wk of postnatal life. Moreover, the significance of this finding of VEP disturbances at the time at which plasma bilirubin reaches peak values was further strengthened after analyzing the outcome of jaundiced animals at the age of $28 \mathrm{~d}$. Most of the $\mathrm{jj}$ Gunn rats who showed prolonged latencies of VEP waves at $21 \mathrm{~d}$ of age died during the 4 th wk of life, whereas most of those who survived till at least $28 \mathrm{~d}$ of age exhibited on d 21 significantly shorter wave latencies. Thus, the prolonged latencies of VEP waves at the age of $21 \mathrm{~d}$ could be considered a sign of neurologic deterioration in rats exposed to neurotoxic serum levels of bilirubin. In contrast, although VEP wave amplitudes were significantly lower in $\mathrm{jj}$ compared with $\mathrm{Jj}$ 21-d-old Gunn rats, there were no amplitude differences between the $\mathrm{jj}$ rats who died and those who survived during the 4th wk of life.

Our developmental VEP study started at the postnatal age of $16 \mathrm{~d}$, when clear VEP recordings could first be obtained in Gunn rats. The patterns displayed by the VEP waves $\left(N_{1}, P_{1}\right.$, and $\left.P_{2}\right)$ in our ether-anesthetized Gunn rats were similar to those reported for awake and unsedated Long-Evans rats (23). The developmental changes in the VEP of Gunn rats were similar to those previously reported for rodents and other species (23-26), i.e. as animals matured, the VEP wave components became clearer, their latencies decreased, and their amplitudes initially increased and thereafter decreased. Further research is required to 1) localize the lesion(s) in the visual pathway that is responsible 
for the VEP abnormalities observed in this study with young $\mathrm{jj}$ Gunn rats; 2) determine whether these VEP abnormalities are indicative of impending death; and 3) elucidate the mechanism by which bilirubin affects the visual and other neural transmission pathways.

A single study of VEP has been conducted so far in two jaundiced human neonates, before and after exchange transfusion for treatment of the hyperbilirubinemia (8). In both cases, the latency of the negative wave component of the VEP shortened after treatment. This finding suggests that at least some of the VEP disturbances observed in either jaundiced human neonates or newborn jj Gunn rats may be reversible and could disappear as soon as bilirubin is removed from blood and cleared from the brain, as is the case after exchange transfusion. In this respect, it is of interest that the wave components of both VEP (this study) and $\mathrm{ABR}(13,15)$ of adult $\mathrm{jj}$ Gunn rats are not very different from those of their $\mathrm{Jj}$ controls. It is possible that young $\mathrm{jj}$ rats with abnormal evoked response patterns die at the earlier stages of development. The survivors, however, may exhibit other signs of bilirubin encephalopathy, such as ataxia, and the VEP or ABR may not reflect them.

It should be pointed out that difficulties with visual perception and gaze $(2,3,27)$ have been reported in infants who developed jaundice in the neonatal period. Thus, the present findings of VEP abnormalities in jj Gunn rats may ultimately be of clinical relevance in the management of neonatal jaundice. Additional studies of VEP and other cortical evoked responses (e.g. somatosensory) may shed further light on the pathogenesis of bilirubin encephalopathy and, thus, contribute to improve the early diagnosis and prevention of impending bilirubin-induced brain damage in the neonatal period.

Acknowledgment. The authors thank Ana Fibach for her help in the preparation of this manuscript.

\section{REFERENCES}

1. Holmes GE, Miller JB, Smith EE 1968 Neonatal bilirubinemia in production of long-term neurological deficits. Am J Dis Child 116:34-43

2. Hyman CB, Keaster J, Hanson V, Harris I, Sedgwick R, Wursten H, Wright AR 1969 CNS abnormalities after neonatal hemolytic disease and hyperbilirubinemia. Am J Dis Child 117:395-405

3. Naeye RL 1978 Amniotic fluid infections, neonatal hyperbilirubinemia and psychomotor impairment. Pediatrics 62:497-503

4. Chisin R, Perlman M, Sohmer H 1979 Cochlear and brain stem responses in hearing loss following neonatal hyperbilirubinemia. Ann Otol Rhinol Laryngol 88:352-357

5. Kaga K, Kitazumi E, Kodama K 1979 Auditory brain stem responses of kernicterus infants. Int J Pediatr Otorhinolaryngol 1:255-264
6. Lenhardt ML, McArtor R, Bryant B 1984 Effects of neonatal hyperbilirubinemia on the brainstem electric response. I Pediatr 104:281-284

7. Nakamura H, Takada S, Shimabuku R, Matsuo M, Matsuo T, Negishi H 1985 Auditory nerve and brainstem responses in newborn infants with hyperbilirubinemia. Pediatrics 75:703-708

8. Chin KC, Taylor MJ, Perlman M 1985 Improvement in auditory and visua evoked potentials in jaundiced preterm infants after exchange transfusion. Arch Dis Child 60:714-717

9. De Vries LS, Lary S, Whitelaw AG, Dubowitz LMS 1987 Relationship of serum bilirubin levels and hearing impairment in newborn infants. Early Human Dev 15:269-277

10. Nwaesei CG, Van Aerde J, Boyden M, Perlman M 1984 Changes in auditory brainstem responses in hyperbilirubinemic infants before and after exchange transfusion. Pediatrics 74:800-803

11. Perlman M, Fainmesser P, Sohmer H, Tamari H, Wax Y, Pevsmer B 1983 Auditory nerve-brainstem evoked responses in hyperbilirubinemic neonates. Pediatrics 72:658-664

12. Wennberg RP, Ahlfors CE, Bickers R, McMurtry CA, Shetter JL 1982 Abnormal auditory brainstem response in a newborn infant with hyperbilirubinemia: improvement with exchange transfusion. J Pediatr 100:624-626

13. Lenhardt ML, Clarke AM, Harkins SW 1986 High frequency hearing in jaundiced rats. J Aud Res 26:19-25

14. Levi G, Sohmer H, Kapitulnik J 1981 Auditory nerve and brain stem responses in homozygous jaundiced Gunn rats. Arch Otorhinolaryngol 232:139-142

15. Shapiro SM, Hecox KE 1989 Brain stem auditory evoked potentials in jaundiced Gunn rats. Ann Otol Rhinol Laryngol 98:308-317

16. Uziel A, Marot M, Pujol R 1983 The Gunn rat: an experimental model for central deafness. Acta Otolaryngol (Stockh) 95:651-656

17. Shapiro SM, Hecox KE 1988 Development of brainstem auditory evoked potentials in heterozygous and homozygous jaundiced Gunn rats. Dev Brain Res 41:147-157

18. Ahlfors CE, Bennett SH, Shoemaker CT, Ellis WG, Davis SL, Wennberg RP Goetzman BW 1986 Changes in the auditory brainstem response associated with intravenous infusion of unconjugated bilirubin into infant rhesus monkeys. Pediatr Res 20:511-515

19. Dyer RS, Howell WE 1982 Acute triethyltin exposure: effects on the visua evoked potential and hippocampal afterdischarge. Neurobehav Toxicol Teratol 4:259-266

20. Fox DA, Lewkowski JP, Cooper GP 1977 Acute and chronic effects of neonata lead exposure on development of the visual evoked response in rats. Toxico Appl Pharmacol 40:449-46

21. Lorenzana-Jimenez M, Salas M 1985 Effects of neonatal toluene exposure on the development of evoked and spontaneous cortical activity in the rat. Neurobehav Toxicol Teratol 7:215-220

22. Michaelsson M 1961 Bilirubin determination in serum and urine. Studies on diazo-methods and a new copper-ozopigment method. Scand $\mathrm{J}$ Clin Lab Invest 1 (suppl):46-47

23. Rigdon GC, Dyer RS 1987 Ontogeny of flash-evoked potentials in unanesthetized rats. Int J Dev Neurosci 5:447-454

24. Ellingson RJ, Wilcott RC 1960 Development of evoked responses in visual and auditory cortices of kittens. J Neurophysiol 23:363-375

25. Fox MW 1968 Neuronal development and ontogeny of evoked potentials in auditory and visual cortex of the dog. Electroencephalogr Clin Neurophysioi 24:213-226

26. Rose GH, Lindsley DB 1968 Development of visually evoked potentials in kittens: specific and non-specific responses. J Neurophysiol 31:607-623

27. Hoyt CS, Billson FA, Alpins N 1978 The supranuclear disturbances of gaze in kernicterus. Ann Ophthalmol 10:1487-1492 